\title{
Educador social eu sou: quem eu era e no que me tornei, como e com quem...
}

\section{Social educator, what I am: who I was and what I became, how and with whom...}

\section{Educador social yo soy: quién era y en qué me convertí, cómo y con quién...}

\author{
Ana Maria Vieira ${ }^{1}$ \\ Ricardo Vieira ${ }^{1}$ \\ José Carlos Marques ${ }^{1}$
}

DOI: http://dx.doi.org/10.20435/serie-estudos.v26i57.1573

\begin{abstract}
Resumo: Este texto resulta da análise dos primeiros dados recolhidos no âmbito de um projeto maior que se dá pelo nome de "Educadores sociais em Portugal: quem são, onde estão e o que fazem? Identidades e Transformações". Os seus autores estão ligados ao desenvolvimento da educação/pedagogia social em Portugal e dos seus profissionais, os educadores sociais, que têm acompanhado em formações de licenciatura, mestrado e doutorado, em estágios em diversas instituições socioeducativas, de reinserção social, de acolhimento familiar, e em escolas que assumem que a educação começa fora da escola, passa por ela e estende-se para além dela. 0 educador social é, assim, um mediador intercultural, um mediador socioeducativo, um construtor de pontes entre culturas, pessoas, grupos e comunidades, que tem formação académica para o efeito, mas que, como aqui pretendemos apontar, nas palavras dos sujeitos escutados, tem momentos marcantes que só ele pode assinalar, momentos formativos que considera significativos na sua história de vida para chegar a ser o profissional que é.
\end{abstract}

Palavras-chave: hermenêutica; autoformação e heteroformação; autobiografia.

Abstract: This text results from the analysis of the first data collected in the context of a larger project called "Social Educators in Portugal: who are they, where are they and what do they do? Identities and Transformations". Its authors are linked to the development of social education/ pedagogy in Portugal and of its professionals, the social educators, who have accompanied them in undergraduate, master's, and doctoral training, in internships in various socio-educational institutions, social reintegration, family care, and in schools that assume that education begins outside school, passes through it and extends beyond it. The social educator is, therefore, an

${ }^{1}$ Escola Superior de Educação do Instituto Politécnico de Leiria (ESECS.IPLeiria); Centro Interdisciplinar de Ciências Sociais da Universidade Nova de Lisboa (CICS.NOVA.IPLeiria), Leiria, Portugal. 
intercultural mediator, a socio-educational mediator, a bridge-builder between cultures, people, groups, and communities, who has academic training for that purpose, but, as we intend to point out, in the words of the subjects listened to, has remarkable moments that only he can mark, formative moments that he considers significant in his life history to become the professional he is.

Keywords: hermeneutics; self-training and heteroforming; autobiography.

Resumen: Este texto es el resultado del análisis de los primeros datos recopilados en el contexto de un proyecto más amplio que lleva el nombre de "Educadores sociales en Portugal: ¿quiénes son, dónde están y qué hacen? Identidades y Transformaciones". Sus autores están vinculados al desarrollo de la educación/pedagogía social en Portugal y de sus profesionales, los educadores sociales, que los han acompañado en la formación de pregrado, maestría y doctorado, en pasantías en diversas instituciones socioeducativas, de reinserción social, de cuidado familiar, y en las escuelas que asumen que la educación comienza fuera de la escuela, pasa por ella y se extiende más allá de ella. El educador social es, por tanto, un mediador intercultural, un mediador socioeducativo, un puente entre culturas, personas, grupos y comunidades, que cuenta con una formación académica para tal fin, pero, como pretendemos señalar, en palabras de los sujetos escuchados, tiene momentos notables que solo él puede marcar, momentos formativos que considera significativos en su historia de vida para convertirse en el profesional que es.

Palabras clave: hermenéutica; autoformación y heteroformación; autobiografía.

\section{INTRODUÇÃO}

Este texto é parte de uma investigação em curso em Portugal que se intitula "Educadores sociais em Portugal: quem são, onde estão e o que fazem? Identidades e transformações" e que, num largo espetro, tem como objetivos fundamentais: aprofundar os estudos sobre a emergência da profissão do Educação Social (ES) em Portugal; compreender a construção do profissional da ES nas várias instituições de Ensino Superior; caracterizar os profissionais de ES em termos de idade, género, experiência profissional e áreas de intervenção; mapear os locais de trabalho onde atuam os educadores sociais; identificar redes de colaboração entre educadores sociais e outros profissionais do trabalho social; compreender as ligações entre as trajetórias sociais e as motivações para a ES; compreender a influência do ensino superior e o peso do currículo oculto na construção do educador social.

Neste primeiro ensaio desse projeto planificado para três anos, damos conta dos esboços iniciais da primeira etapa investigativa, assente em entrevistas exploratórias de natureza biográfica, em autobiografias de educadores sociais no final da trajetória académica - o projeto contempla escuta ativa no início e 
também no final, (trans)formação de que só poderemos dar conta daqui a três anos.

Pretendemos, assim, contribuir para uma primeira aproximação à construção/reconstrução do eu profissional que envereda pela Educação/Pedagogia Social: "Educador social eu sou: quem eu era e no que me tornei, como e com quem...". Um contributo, portanto, para o estudo da construção do eu profissional, de hoje, destes educadores sociais.

Recorremos, essencialmente, às próprias palavras dos educadores, ao jeito de Oscar Lewis (1970), um antropólogo americano que se celebrizou, em termos metodológicos, por fazer antropologia urbana cruzada com a literatura, usando as vozes dos próprios sujeitos que entrevistou. Os Filhos de Sanchez é uma das muitas obras que Lewis produziu com quase todos os membros desta família. Fêlo de um modo inovador, dando voz aos próprios sujeitos das suas investigações, tornando-os assim autores e coautores da pesquisa. As biografias cruzadas são uma das várias inovações metodológicas que nos deixou. No nosso caso, estamos a recorrer às reflexões autobiográficas sobre a entrada no curso de Educação Social e a construção do eu profissional de hoje, intercaladas com escassas interpretações para evitar uma espécie de tradução cultural.

Gaston Pineau e Jean-Louis Le Grand (1993) afirmam que as práticas de "histórias de vida" são muito variadas. Questionam as novidades para que estas práticas remetem: se para a sede humana do saber e do poder; se para a própria vida; se para as Ciências Humanas; se para a intervenção social; se para a autoformação dos atores sociais; se para uma arte de construir conhecimento, ou de governar. A problemática inscreve-se, assim, por um lado, na questão de saber se traduzir a vida em palavras é uma ilusão ou uma revolução na construção do saber científico; por outro lado, como começá-la e como terminá-la. A problemática das histórias de vida é trabalhada por estes autores como processo de pesquisa e construção de sentido, a partir de factos temporais pessoais.

Em síntese, procuraremos aqui apresentar essencialmente o ponto de vista do outro, na busca de uma auto-hermenêutica (GEERTZ, 1989, 2001) destes profissionais da intervenção socioeducativa entre as aprendizagens da escola da vida e as aprendizagens da vida na escola. Como refere Dominicé (1992), "[...] a vida, tal como a sala de aula são espaços de aprendizagem e não se trata de colocar em oposição um e outro, mas de os situar na sua complementaridade" (p. 7). 
António Nóvoa (apud JOSSO, 2002), a principal referência portuguesa nos estudos biográficos, diz, no prefácio a um livro de Josso (2002), outra das grandes referências francófonas desta epistemologia de investigação, que "[...] o seu contributo principal passa pela definição de histórias de vida como metodologia de investigação-formação, isto é, como metodologia onde a pessoa é, simultaneamente, objeto e sujeito de formação" (p. 10). Nas próprias palavras de Christine Josso (2002), "[...] os processos de formação dão-se a conhecer pelo ponto de vista do aprendente, em interações com outras subjetividades" (p. 28).

\section{METODOLOGIA E SUJEITOS DE ESTUDO}

Nesta fase do projeto, enveredámos pelo recurso à reflexão biográfica (JOSSO, 2002; VIEIRA, 1999). Interagimos com licenciados em Educação Social e solicitámos que os voluntários escrevessem, ao longo de três meses, sobre as seguintes orientações dadas previamente: De onde vem a minha motivação e predisposição para a área da educação social? Quem eu era e como eu era no início do curso? Em quem me transformei durante e após o curso, em termos pessoais e técnico-profissionais? O que mudou em mim com a formação em educação social? Nem sempre os licenciados e já profissionais foram capazes de manter esta estrutura nas suas reflexões. Daí que falemos de um texto em esboço, de uma investigação que nos vai fazer regressar ao terreno e às entrevistas biográficas várias vezes (POIRIER; CLAPIER-VALLADON; RAYBAUT, 1995).

Surgiram, assim, sete primeiras autobiografias, em outubro de 2020, de que aqui exploramos, sumariamente, apenas duas: a da Joana e a da Sara.

Para ajudar à organização das narrativas, sugerimos ainda alguns marcadores temporais para a reflexão, caso fizessem sentido na vida de cada um: a entrada na educação social; as primeiras aulas; hesitações, receios e motivações iniciais; visão inicial da profissão de educador(a) social; visão atual da profissão de educador(a) social; mudanças pessoais ocorridas na formação; contributos para essas mudanças (pessoas e acontecimentos); incidentes críticos durante a licenciatura (acontecimentos, pessoas, interações, momentos/tempos/espaços de rutura com ideias feitas e reconstrução de novos olhares...); exemplos de aprendizagens concretas (onde e com quem); convicções e motivações de ontem e de hoje; ligações e distinções entre a educação social e outras áreas afins. 
Na constatação das práticas multiformes das histórias de vida, Pineau e Le Grand (1993) debruçam-se sobre as práticas disciplinares de investigação nas ciências que designam de antropo-sociais. Destacam a etnografia e as histórias de vida social, onde se trata, normalmente a propósito de um objeto preciso, de recolher uma ou mais histórias de vida e de as cruzar entre si. Na tradição antropológica, e a partir da escola de Chicago, a corrente aparece ligada a outras formas de investigar no terreno. Trata-se de procurar compreender o sentido que os atores sociais dão às suas próprias práticas e aos acontecimentos de que são protagonistas, metodologia próxima da sociologia compreensiva decorrente de Max Weber. A obra de Pineau e Le Grand (1993) dá particular atenção também à sociologia, à psicologia e psicanálise, à literatura e linguística e à educação e formação de adultos. Quanto à primeira, a obra debruça-se sobre as influências de Daniel Bertaux, em França, e a mudança qualitativa ocorrida nos estudos sociológicos, marcados muitas vezes por meros inquéritos estatísticos. $\mathrm{O}$ trabalho biográfico orienta-se, aqui, no sentido de uma análise de práticas e processos sociais. Quanto à última, refere-se a história de vida não só como abordagem de investigação, mas também como prática de formação (VIEIRA, 1999).

Como diz Pierre Bourdieu (1993) na introdução que dirige ao leitor de La Misère du Monde, com uma grande equipa da Escola de Altos Estudos em Ciências Sociais, trata-se de apresentar, essencialmente, um olhar compreensivo, recorrendo às próprias palavras dos sujeitos estudados - no caso dessa investigação da equipa de Bourdieu, através de entrevistas aprofundadas; neste caso, através de retratos autobiográficos. Tal como em La Misère du Monde (Bourdieu, 1993), usamos também títulos e subtítulos retirados das próprias biografias para orientar as leituras possíveis:

Na transcrição da entrevista, ela mesma [...] o título e os subtítulos (sempre emprestados e retirados do inquérito), e sobretudo o texto com que precedemos o diálogo, estão lá para dirigir o olhar do leitor através dos traços pertinentes que a perceção distraída e desarmada deixaria escapar. Eles têm por função recordar as condições sociais e os condicionamentos de que o autor do discurso é o produto, a sua trajetória, a sua formação, as suas experiências profissionais, tudo aquilo que se dissimula e desaparece, tantas vezes, no discurso transcrito. (BOURDIEU, 1993, p. 8, tradução nossa). 


\subsection{Joana}

Joana, licenciada em Educação Social e a realizar um mestrado na área da Mediação Intercultural, começou por estudar Direito durante dois anos. Concluiu que precisava de estudar matérias que se prendessem mais com o lado humano, social e socioeducativo. A doença do avô veio a revelar-se decisiva para abandonar o curso de Direito e começar a estudar Educação Social. A Joana reconhece, hoje, que aprendeu muitas coisas com esta licenciatura, mas também sabe que aprendeu muito com o que designa de "a escola da vida".

\subsubsection{Futuro nebuloso}

O meu percurso até chegar ao curso de Educação Social foi bastante turbulento, as dúvidas sobre qual caminho tomar e as decisões sobre um futuro, que se apresentava um pouco nebuloso, eram demasiadas. Creio que por ser a primeira do meu núcleo familiar a frequentar o ensino superior tenha-se colocado uma grande pressão na escolha de qual curso frequentar. Na altura encontrava-me perdida entre todas as opções que poderia vir a escolher, sendo que primeiramente enveredei pelo curso de Direito na Faculdade Clássica de Lisboa (FDUL), na qual estudei durante dois anos. No meu primeiro contacto com o "Mundo Universitário" e neste curso, cresci muito enquanto pessoa e aprendi a importância da eloquência, imagem e postura, tanto para triunfar no mercado de trabalho como para nos destacarmos na própria sociedade.

\subsubsection{Do jurídico ao humanitário}

No entanto, mais do que cumprir e fazer cumprir a letra da lei, percebi que a minha "paixão" recaía em muito mais do que aquele "mundo" me conseguiria vir a oferecer. O meu propósito era muito maior do que aquele que julgava ter à partida: fazer ouvir a voz de quem mais precisasse, indo para além de uma ação meramente jurídica e legislativa, e seguir por o campo mais humanitário da questão, o campo social, essa sim, era a minha verdadeira vocação. As minhas crenças numa sociedade coesa não recaíam nas premissas de nenhum decreto-lei, lei ou mesmo Constituição, acreditando que, mais do que uma sociedade igualitária, deveríamos, antes, zelar pela necessidade abrupta da equidade - de darmos a todos oportunidades de acordo com as suas necessidades e fragilidades, não beneficiando ou negligenciando ninguém, apenas partindo do pressuposto da existência de 
igualdade de acessos, direitos e oportunidades, zelando pela justiça social como máxima.

\subsubsection{Os valores familiares e a referência do avô}

Com os meus pais e avós maternos aprendi grandes valores e princípios que jurei sempre cumprir e priorizar, sempre me ensinaram a dar o meu melhor e lutar pelo que queria. Para mim lidar com a faixa etária sénior nunca foi um problema ou um aborrecimento, sempre tomei esse tempo como um momento de aprendizagem e partilha de grande importância. Os meus avós ensinaram-me a respeitar e valorizar a partilha de pontos de vista diferentes e a colocar-me em perspetivas e visões para além da minha. Quando o meu avô adoeceu, estava no segundo ano da minha primeira licenciatura, a demência tomou conta das memórias dele, lentamente, e nesse ano a doença manifestava-se cada vez com mais força e intensidade. A incompreensão e o sentimento de incapacidade tomaram conta de mim e fizeram-me querer buscar respostas ou/e soluções para conseguir ajudar, de que forma fosse. Sentia que um dos grandes pilares da minha vida tinha começado a desabar e junto com ele desabaram algumas das conviç̧ões que eu tinha sobre o meu futuro e sobre a forma como o estava a construir. Quando faleceu, nesse mesmo ano, procurei recomeçar e comecei a reestruturar todo o meu projeto de vida até ao momento.

\subsubsection{Educação Social - "uma porta mágica que mudou e transformou a minha vida"}

A Educação Social surge como uma porta mágica que mudou e transformou a minha vida radicalmente. Logo no meu primeiro ano da Licenciatura de Educação Social, na ESECS ${ }^{2}$, comecei a entender certos conceitos e contextos de uma forma mais holística, encontrando no Educador Social um profissional humano, dedicado, de pensamento revolucionário e totalmente pró-ativoque era tudo o que um dia eu desejava poder vir a ser a nivel profissional! A minha grande questão, inicialmente, era restringir-me a um único grupo em particular, porque o meu maior desejo era, e continua a ser, ter contacto com um pouco de todos os tipos de grupos (crianças, jovens, grupos de risco, adultos, seniores) de forma a explorar diretamente as diferentes e diversas capacidades multifacetadas da profissão.

\footnotetext{
${ }^{2}$ Escola Superior de Educação e Ciências Sociais (ESECS), do Instituto Politécnico de Leiria.
} 
Na verdade, desde pequena que acredito que vou mudar o Mundo, acredito que todos quando somos pequenos sonhamos e pensamos da mesma forma, e quando descobri o curso de Educação Social vi o meu sonho ganhar asas e entendi que a mudança era possivel e atingivel, por entre pequenas ações e intervenções seria possível mudar o mundo, uma pessoa de cada vez. Com este curso entendi que o tempo certo não é o que a sociedade estipula para nós, mas sim o momento que sentimos como ideal para pormos em prática os nossos projetos de vida e perceber que nunca é tarde demais para os construirmos e atingirmos. Aprendi a valorizar a bagagem cultural de cada pessoa e aprendi que a diferença não deve ser encarada enquanto um problema, mas sim como uma mais-valia.

\subsubsection{A aprendizagem na escola da vida}

Aprendi imensas coisas com esta licenciatura, com os professores responsáveis por lecionar as nossas unidades curriculares, mas também aprendi, e muito, com a "escola da vida", com as amizades que travei, com as pessoas que foram fazendo parte deste percurso, com o contacto com a vida como nunca tinha vivido. Também eu mudei, mas a mudança faz parte, é essencial ao ser humano, o pior da vida é a estagnação, a ignorância do permanecer ignorante, ser Educador Social também é isto - impulsionar a mudança, abraçá-la! No fundo recriei-me e inventei-me durante toda esta viagem, no final tudo não passou de uma metamorfose, uma das muitas que a vida tem. Em mim hoje mora uma agente de intervenção social, uma mediadora, uma verdadeira profissional da relação. O percurso ainda não terminou, porque todos os dias são uma aprendizagem e, na verdade, nunca paramos de aprender. Foram três anos para terminar esta licenciatura e, simultaneamente, três anos para eu a conseguir definir. Para mim a Educação Social é: uma profissão rica e multidimensional, que carrega consigo inúmeras tarefas e inúmeras exigências. É muito mais do que um trabalho, é uma escolha de vida... uma opção que nos faz repensar nas coisas tal como são, que desafia a sociedade e toda a sua estrutura. Ser Educador Social é saber ouvir, aconselhar, entender e não-julgar, é sobre empoderar o outro e mostrar-lhe os caminhos que podem ser tomados e de que maneira estes podem determinar o rumo das nossas vidas. Acaba por ser uma profissão que pretende educar ou reeducar o "outro" a viver em sociedade e com a sociedade.

\subsection{6 "Vivemos num estado de emergência"}

Nos dias que correm e devido à situação em que nos encontramos, dado o Covid-19, verifico cada vez mais uma "crise" no sistema social e na imprescindibilidade de reeducar a sociedade para as novas realidades que se têm vindo a sentir. Mais do que nunca é necessário repensar na sociedade 
enquanto um elemento que venha abranger um contexto verdadeiramente multicultural, coeso e inclusivo na sua íntegra, que vá para além dos "conformismos" (de uma ideia que no seu seio é individualista e restrita, reconduzindo à própria exclusão social). Vivemos num estado de emergência social, que faz urgir a iminência de respostas sociais com a maior das urgências, sendo, na minha perspetiva, uma mais-valia dar-se primazia à construção de equipas multidisciplinares, capazes de trabalhar em rede para o proveito da sociedade, tomando o Educador Social enquanto um agente essencial para a readaptação social a este novo Mundo. Realce-se a importância, ainda, deste profissional para combater o distanciamento social. No contexto pandémico o que urge manter é um distanciamento físico, nunca social. No momento que vivenciamos é fulcral zelar pelo bem-estar e sustentabilidade social, e não impulsionar ideias que nos reconduzam a uma segregação abismal de toda a estrutura, apoio e intervenção neste campo.

\subsubsection{Leiria, cidade de luz}

Importa relembrar Leiria, que, por si própria, foi um lugar de introspeção, transformação e crescimento pessoal inegável. Cidade de luz, com gosto a saudade e lembrança para todo o sempre, onde ecoarão guitarradas bem entoadas da nossa "linda Leiria", sapatos que batem sonoramente ao longo das pedras da calçada, a memória de quem me deu um pedacinho desta cidade desde que sou gente e as aprendizagens académicas e pessoais que levo comigo na minha bagagem. [...]

\subsection{Sara}

A Sara estudou na Escola Superior de Educação e Ciências Sociais do Instituto Politécnico de Leiria entre 2017 e 2020. Era a mais velha da turma e gostava muito de intervir. Estranhava que os outros o fizessem pouco. Por vezes era chamada, carinhosamente, de "velhinha", por já ser casada e mãe de filhos. Considera fundamental a intervenção socioeducativa a montante, na sua vertente preventiva.

\subsubsection{Intervir a montante}

É premente o reforço da intervenção a montante, num paradigma de prevenção e promoção da Saúde Mental, com participação do Educador Social nas equipas multidisciplinares de diferentes âmbitos de intervenção. Apelando, deste modo, a este investimento por parte das políticas governamentais, visando dar 
resposta ao presente e ao futuro da Saúde Mental em Portugal, perspetivando uma dignidade social equitativa. Dotar de conhecimentos, através de literacia para a saúde, será um necessário caminho a percorrer. [...]

\subsubsection{O educador social, ontem e hoje}

[...] Esta era a minha visão inicial de um possível âmbito de intervenção, o Educador Social enquanto profissional multifacetado, criativo, dotado de capacidade empática, a integrar a equipa multidisciplinar de um serviço de psiquiatria e saúde mental. Volvidos três anos, muito haveria a acrescentar; o Educador Social é, também, um especialista de mãos vazias, sem receitas prontas ou miraculosas, tal como expõe, com mestria, Isabel Baptista. A entrada para esta licenciatura foi criteriosamente ponderada (com a condicionante de não ser lecionada em regime pós-laboral). Identifico-me verdadeiramente com o âmbito de intervenção que proporciona. Era justamente isto. Primeira e única opção. Início do período de aulas, após a frequência, com sucesso, do curso preparatório M23, setembro de 2017, primeiro dia (reunião com o Senhor Professor Coordenador de Licenciatura), uma multa por excesso de velocidade, numa que era apenas uma das muitas viagens que se anteviam. Pensei: isto não é uma praxe integrativa (respeito e entendo o propósito da praxe, mas recusei-a, por opção), é um aviso; o ritmo iria, por certo, ser perturbador: articular a vida familiar, profissional e o curso, ainda que fosse imperativo cumprir o código da estrada. O primeiro ensinamento foi este, educação para uma cidadania responsável. Ainda que nada justifique os inúmeros atrasos que, após o pedido de permissão para entrar na já iniciada aula, sempre me foi concedido. Agradeci, sempre.

\subsubsection{Memórias: "estudei muito..."}

Na memória, ficou, conjuntamente, outubro de 2017, o grande incêndio na Mata Nacional de Leiria levou a que a ESECS fosse evacuada e, eu a refletir, numa das tais inúmeras viagens de regresso diário a casa, urge mais elou diferente (re)educação ambiental, sem saber, ainda, a verdadeira dimensão daquela catástrofe ambiental... pouco restara do Pinhal do Rei. A Educação Social parecia-me viável e necessária, presente em diferentes prismas do quotidiano. Parece que não me enganei. No entretanto, a adaptação à rotina algo exigente, a dificuldade em alguns conteúdos de determinadas unidades curriculares, o constatar que boa vontade não chega, era preciso adquirir competências, era preciso trabalhar muito. E trabalhei muito, estudei muito, escrevi guiões, construí cenários, 
planifiquei e dinamizei atividades, pensei coreografias, experimentei âmbitos de intervenção; "trinta por uma linha" e muito mais. Não existiram poções mágicas, nem um qualquer dom, mas eu desejei-o muitas vezes. Porém, em vão (escrevo estas palavras a sorrir). Sempre conhecedora das dificuldades, no meu registo discreto e ponderado, fui construindo o percurso, pareceu-me moroso, trabalhoso, mas enriquecedor, de uma riqueza que eu almejava, há muito.

\subsection{4 "Mãe, tenho saudades tuas, posso?"}

A exigência para comigo própria levou-me a testar alguns limites, embrenhada nos estudos. Os meus reclamavam a minha presença, disponibilidade e entrega, à qual os habituara desde sempre. "Mãe, tenho saudades tuas, posso?". Então (re)organizava-me e desdobrava-me, sem nunca perder o foco. Eu sou uma cuidadora, por excelência, por isso foi ainda mais difícil. Aguardei anos para retomar os estudos (outras prioridades prevaleceram), era um projeto apenas adiado, daí este empenho, esta motivação... Encontrara o curso desejado, não podia abrandar. $O$ ensino superior não se compadece com a saudade de um filho. É assim, impiedoso. A motivação intrínseca em conhecer era imensa e, findado cada semestre, estudava os conteúdos que mais gostava; propus-me, assim, realizar 5 meIhorias de classificação, em 5 semestres consecutivos. Parecia uma estratega, mas não... valeu-me o modo como me impliquei e alguma persistência, obtive sempre a ambicionada melhoria. Dava-me alento alcançar resultados a estudar, apenas a resolver um exame escrito. Realização pessoal foi o que senti aquando a chegada do certificado de conclusão de curso, via $\mathrm{CTT}^{3}$. Média de 17 valores! Que bom, a minha dedicação havia sido reconhecida.

\subsection{5 "Analisei cada crítica que me foi dirigida"}

Analisei cada crítica que me foi dirigida, registava, mentalmente, cada palavra proferida pelos Professores, queria melhorar continuamente, entender cada reparo, cada observação, cada elogio. E eu sabia que havia muito a melhorar, aliás, ainda há, sempre haverá. Cada Professor, seu método, de ensinar e de avaliar; identifiquei-me muito com determinados, com outros nem por isso, mas tudo são aprendizagens. Talvez sentisse falta de determinada discriminação positiva, afinal, não éramos todos um grupo de jovens. Momentos houve que não gostei, ainda que poucos. Apenas me parece

\footnotetext{
${ }^{3}$ Correios e Telecomunicações de Portugal.
} 
razoável e feliz na terra dos sonhos, onde "toda a gente trata a gente toda por igual", só mesmo aí... Ouso dizer que falta essa capacidade a determinados Professores, a de adequar a terminologia ao contexto real da sala de aula, $e$ não apenas a uma turma de jovens estudantes. Quiçá estivesse demasiado desperta para essas abordagens, mas fiz sempre por me incluir na turma e na comunidade académica, desde o primeiro dia. E alcancei.

\subsection{6 "Os muitos trabalhos de grupo eram feitos atempadamente, era eu quem ditava os tempos, assumindo a logística da agenda"}

Sempre considerei que o espaço físico não poderia, de todo, ser condicionante às práticas educativas, pois tenho a capacidade de me adaptar ao existente, mas as salas de aula gélidas do bloco A testavam-me a cada novo dia de inverno. Entre outras particularidades inerentes ao próprio bloco, com espaços que clamam por intervenção/manutenção, situação que estará, por certo, identificada por quem de direito. Conquistei algumas verdadeiras amizades (entre um ou outro dissabor), as quais me exigiam uma mensagem de texto, quando regressava diariamente a casa, vinda da ESECS, apenas na hora do seu fecho. Os muitos trabalhos de grupo eram feitos atempadamente, era eu quem ditava os tempos, assumindo a logística da agenda. "Colegas, vão descansar, a velhinha (como carinhosamente ainda me chamam) já calçou as pantufas, em breve vai dormir". E foi assim muitos dias, muitas noites. Que luta! Guardo, também, nestas amizades, a essência da Educação Social, pois tecemos laços, alicerçámos o conhecimento na amizade. Muito Ihes devo. Interessante, dizem-me exatamente o mesmo. Que maravilha!

\subsubsection{O educador social como um catalisador de esperança}

Apraz-me dizer que todas as aprendizagens realizadas em contexto de Estágio Curricular contribuíram para o término deste ciclo de estudos, enquanto modo de complementar e implementar conhecimentos adquiridos em contexto de sala de aula. O Educador Social implica-se no exercício da sua atividade, como um catalisador de esperança, num compromisso contínuo de um ímpar contributo, conducente à transformação de uma realidade exigente, por vezes descurada e estigmatizada. Assim, estabelecida esta relação, ficou uma palavra de sincero apreço por dizer, aos Utentes, com os quais tive oportunidade de muito aprender. Foi um privilégio! Nunca o precedente parágrafo teria por mim sido escrito sem esta magnífica viagem ao Universo da Educação Social. Dignifiquei o curso, assim como a ESECS, debati-me pelas práticas pedagógicas e unidades 
curriculares do curso, pois as comparações com outros estabelecimentos de ensino e outras licenciaturas eram inevitáveis, a equipa multidisciplinar que integrei era díspar, o meu trabalho foi criteriosamente observado, enquanto primeira estagiária da Licenciatura em Educação Social no Ambulatório do Serviço de Psiquiatria do Centro Hospitalar do Médio Tejo. Apliquei, sempre que possivel, os conhecimentos adquiridos e aprofundeioutros quemeeramfundamentaisaumadequadodesempenho. Foiumsemestreatípico, um verdadeiro desafio, precipitado pela situação pandémica experienciada. As vicissitudes da vida fomentam a resiliência, impliquei-me para que assim fosse. Os tempos de adversidade e incerteza que experienciamos atualmente são um desafio às competências e ao saber de todos, ainda que o Educador Social, pelas características fundamentais do saber profissional, incumbe-Ihe uma acrescida responsabilidade. A reflexividade, polivalência técnica, criatividade, adaptabilidade e dinamismo são parte dessas características que, empregadas metodicamente, levam o profissional a melhor interpretar as realidades sociais, podendo, assim, praticar uma filosofia hermenêutica, nunca descurando a capacidade empática, que the é compromisso absoluto pela ética profissional e, essencialmente, pela valorização própria dos princípios morais. A empatia é a esperança na Humanidade, acredito! Guardarei, primordialmente, deste percurso académico, os bons momentos: 0 Professor que, no término do semestre, declamou, de forma exímia, "Cântico Negro", de José Régio, e eu que pensava que Direito nada teria a ver com poesia, pois surpreendi-me; a gentileza, qualidade que tanto admiro, de alguns professores; o cavalheirismo de outros; o incentivo pela continuação e progresso do percurso académico; a disponibilidade verdadeira para o esclarecimento de dúvidas (eu sempre tinha questões); os breves minutos que me foram, ocasionalmente, concedidos para terminar as frequências (nunca escrevia tudo o que tencionava, que desespero); os exemplos na primeira pessoa, que tanto me elucidavam; os detalhes de cada aula, e os ensinamentos de todos. Os ganhos foram elevados. O saldo é amplamente positivo. A todos, obrigada! Barco que não tem rota não beneficia de vento algum. Metaforicamente, o Educador Social pode colaborar a (re)definir trajetórias de vida, como quem (re)desenha rumos, através de singulares projetos de vida, pedagógicos e socioeducativos, reconhecendo as especificidades de cada indivíduo, visando promover a reabilitação, capacitação e autonomização de quaisquer, a quem se propõe intervencionar. Concebendo o seu trabalho através de uma perspetiva educativa, transformadora e emancipatória; promovendo, ainda, uma escuta ativa, dando permanente voz e poder de escolha. Sendo o objetivo principal da Educação Social o de incluir o indivíduo na sociedade, priorizando e valorizando as suas potencialidades, para que assim este possa voltar a ser o protagonista da sua pró- 
pria vida. Esta é a minha presente visão da Educação Social, é com este olhar, atento, que concebo esta etapa do percurso académico. Aprendi. A propósito de uns estudos, após o término da licenciatura, deparei-me como seguinte pensamento (ideologias políticas à parte), do qual partilho, agora sob o olhar reflexivo de um Educador Social: "A prioridade absoluta tem de ser o ser humano. Acima dessa, não reconheço nenhuma outra prioridade" (Saramago). Concluída esta etapa do percurso, muito mudou... o conhecimento capacita-nos, para além da nossa condição. Somos pessoas diferentes, transformadas.

\section{CONSIDERAÇÕES FINAIS}

Não foi, de todo, alcançado ainda o objetivo pretendido com este estudo. Trata-se de uma investigação alargada, com recurso a uma complexidade e variedade metodológica que, no seu todo, e daqui a três anos, acreditamos nos dará ainda mais dados para pensarmos a construção e reconstrução identitárias dos educadores sociais em Portugal.

Como se trata do início de um projeto de investigação, estamos em crer que nas reflexões seguintes, biográficas, a partir de entrevistas aprofundadas e já mais direcionadas para as questões que agora não foram totalmente cobertas, e nas autobiográficas, que, em segunda instância, cremos que levarão a pensar mais a transformação de si, conseguiremos obter reflexões mais particulares e reveladoras dos incidentes críticos formadores e das pessoas que, de forma positiva ou negativa, contribuíram para a redefinição de determinada identidade pessoal e profissional (VIEIRA, 1999).

\section{REFERENCIAS}

BOURDIEU, P. La misère du monde. Paris: Seuil, 1993.

DOMINICÉ, P. L'histoire de vie comme processus de formation. Paris: L' Harmattan, 1992.

GEERTZ, C. Nova luz sobre a antropologia. Rio de Janeiro: Jorge Zahar Editor, 2001.

GEERTZ, C. A interpretação de culturas. Rio de Janeiro: Guanabara, 1989.

JOSSO, M. C. Experiências de vida e formação. Lisboa: Educa, 2002. 
LEWIS, O. Os filhos de Sanchez. São Paulo: Moraes Editora, 1970.

NÓVOA, A. Prefácio. In: JOSSO, C. Experiências de vida e formação. Lisboa: Educa, 2002. p. 7-12.

PINEAU, G.; LE GRAND, J. L. Les histoires de vie. Paris: PUF, 1993.

POIRIER, J.; CLAPIER-VALLADON, S.; RAYBAUT, P. Histórias de vida: teoria e prática. Lisboa: Celta, 1995.

VIEIRA, R. Histórias de vida e identidades. Porto: Edições Afrontamento, 1999.

\section{Sobre os autores:}

Ana Maria Vieira: Doutora em Ciências da Educação; e mestre em História e Problemas Actuais da Educação pela Universidade de Trás-os-Montes e Alto Douro. Licenciada em Ensino Básico, variante de Matemática e Ciências da Natureza, pela Escola Superior de Educação e Ciências Sociais, Instituto Politécnico de Leiria. Atualmente é professora adjunta no Instituto Politécnico de Leiria. É coordenadora e investigadora integrada do Centro Interdisciplinar de Ciências Sociais da Universidade Nova de Lisboa, polo de Leiria (CICS.NOVA.IPLeiria). E-mail: ana.vieira@ipleiria.pt, Orcid: https://orcid.org/0000-0002-3976-6359

Ricardo Vieira: Agregado em Antropologia da Educação; pós-doutor em Serviço Social; e doutor em Antropologia Social pelo Instituto Superior de Ciências do Trabalho e da Empresa - Instituto Universitário de Lisboa (ISCTE-IUL). Mestre em Antropologia Cultural e Social; mestre em Sociologia da Cultura; e licenciado em Antropologia pela Universidade Nova de Lisboa. Atualmente é Professor Coordenador Principal no Instituto Politécnico de Leiria e Investigador Integrado do Centro Interdisciplinar de Ciências Sociais da Universidade Nova de Lisboa, polo de Leiria (CICS.NOVA.IPLeiria). E-mail: ricardo.vieira@ipleiria.pt, Orcid: https://orcid.org/0000-0003-1529-1296

José Carlos Marques: Agregado em Sociologia pela Universidade Nova de Lisboa. Doutor em Sociologia pela Universidade de Coimbra. Mestre em Sociologia pela Universidade de Coimbra. Licenciado em Sociologia pela Universidade de Évora. Atualmente é Professor Coordenador Principal no Instituto Politécnico de Leiria. Investigador Integrado do Centro Interdisciplinar de Ciências Sociais 
da Universidade Nova de Lisboa, polo de Leiria (CICS.NOVA.IPLeiria). E-mail: jose.marques@ipleiria.pt, Orcid: https://orcid.org/0000-0002-4690-5943

Recebido em: $18 / 03 / 2021$

Aprovado em: 15/05/2021 